\title{
Avi Avidov
}

\section{Not Reckoned among Nations}

The Origins of the So-Called "Jewish Question « in Roman Antiquity

[Nicht zu den Heiden gerechnet. Die Ursprünge der sogenannten »udenfrage« in der römischen Antike.]

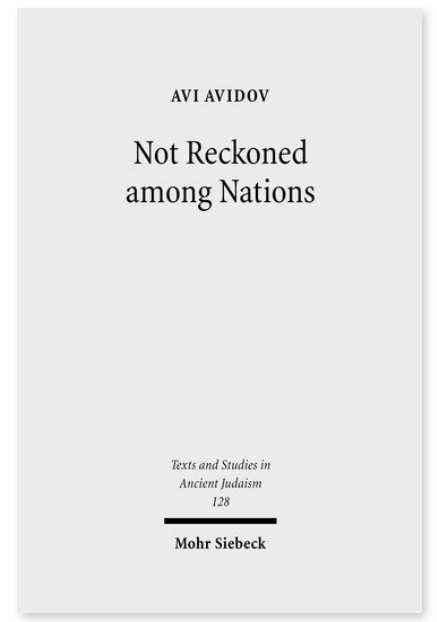

2009. XII, 226 Seiten. TSAJ 128

ISBN 978-3-16-151461-6

DOI 10.1628/978-3-16-151461-6

eBook PDF $104,00 €$

ISBN 978-3-16-150021-3

Leinen $104,00 €$
Veröffentlicht auf Englisch.

Wie in der Moderne, so ging es auch in der römischen Antike bei der sogenannten 'Judenfrage' im Wesentlichen um die Integration der Diaspora Juden in ihre Gastländer. Soziale Integration variiert jedoch in Übereinstimmung mit den

Organisationsprinzipien, die den verschiedenen Gesellschaften zugrunde liegen. Um die Randposition der Juden innerhalb des römischen Reiches zu verstehen, arbeitet Avi Avidov zuerst die Mechanismen heraus, die die Integration der römischen imperialen Gesellschaft überhaupt beeinflussten. Anschließend zeigt er ein allgemeingültiges Modell sozialer Integration in multikulturellen Gesellschaften, das als Ausgangspunkt seiner Untersuchung der Ursachen für die mangelnde Integration der Juden im römischen Reich dient.

Avi Avidov Born 1954; 1996 PhD in ancient history, University of Cambridge, U.K.; taught at the University of Haifa and BeitBerl College, Israel; currently senior lecturer of history at School of Education, Beit-Berl College.

\section{Jetzt bestellen:}

https://mohrsiebeck.com/buch/not-reckoned-among-nations-9783161514616?no_cache=1

order@mohrsiebeck.com

Telefon: $+49(0) 7071-923-17$

Telefax: +49 (0)7071-51104 